\title{
Artificial insemination in marsupials
}

\author{
John C. Rodger ${ }^{\mathrm{a}, *}$, Damien B.B.P. Paris ${ }^{\mathrm{b}}$, Natasha A. Czarny ${ }^{\mathrm{a}}$, Merrilee S. Harris ${ }^{\mathrm{a}}$, \\ Frank C. Molinia $^{\mathrm{c}}$, David A. Taggart ${ }^{\mathrm{d}}$, Camryn D. Allen ${ }^{\mathrm{e}}$, Stephen D. Johnston ${ }^{\mathrm{e}}$ \\ ${ }^{a}$ School of Environmental and Life Sciences, The University of Newcastle, NSW 2308, Australia \\ ${ }^{\mathrm{b}}$ Department of Equine Sciences, Faculty of Veterinary Medicine, Universiteit Utrecht, 3584 CM Utrecht, The Netherlands \\ ${ }^{\mathrm{c}}$ Landcare Research, Private Bag 92170, Auckland 1142, New Zealand \\ ${ }^{\mathrm{d}}$ Royal Zoological Society of South Australia, Frome Rd, Adelaide, SA 5000, Australia \\ e School of Animal Studies, The University of Queensland, Gatton 4343, Australia
}

\begin{abstract}
Assisted breeding technology (ART), including artificial insemination (AI), has the potential to advance the conservation and welfare of marsupials. Many of the challenges facing AI and ART for marsupials are shared with other wild species. However, the marsupial mode of reproduction and development also poses unique challenges and opportunities. For the vast majority of marsupials, there is a dearth of knowledge regarding basic reproductive biology to guide an AI strategy. For threatened or endangered species, only the most basic reproductive information is available in most cases, if at all. Artificial insemination has been used to produce viable young in two marsupial species, the koala and tammar wallaby. However, in these species the timing of ovulation can be predicted with considerably more confidence than in any other marsupial. In a limited number of other marsupials, such precise timing of ovulation has only been achieved using hormonal treatment leading to conception but not live young. A unique marsupial ART strategy which has been shown to have promise is cross-fostering; the transfer of pouch young of a threatened species to the pouches of foster mothers of a common related species as a means to increase productivity. For the foreseeable future, except for a few highly iconic or well studied species, there is unlikely to be sufficient reproductive information on which to base AI. However, if more generic approaches can be developed; such as ICSI (to generate embryos) and female synchronization (to provide oocyte donors or embryo recipients), then the prospects for broader application of AI/ART to marsupials are promising.
\end{abstract}

(C) 2008 Elsevier Inc. All rights reserved.

Keywords: Marsupial, Assisted reproduction, Artificial insemination, Conservation, Estrous synchronization, Cryopreservation, Cross fostering, Pouch young

\section{Introduction}

Marsupials include some of the most highly threatened species in Australia and highly iconic species in great demand by zoos. The development of assisted

\footnotetext{
* Corresponding author at: The Tom Farrell Institute for the Environment, The University of Newcastle, NSW 2308, Australia.

E-mail address: john.rodger@newcastle.edu.au (J.C. Rodger).
}

breeding technology (ART) and artificial insemination (AI) has the potential to advance the conservation and welfare of marsupials. Marsupial semen collection, handling and basic properties were the subject of a paper [1] at the 1977 Symposium of the Zoological Society of London, which led to Paul Watson's landmark book 'Artificial Breeding of Non-Domestic Animals' [2]. However, despite the three decades that have passed AI, and ART generally, have been demonstrated to have the potential to make a significant impact on conservation 
and reproductive management of only one marsupial species, the koala (Phascolarctos cinereus; $[3,4]$ ). In the koala, 32 pouch young have been produced and birth rates following $\mathrm{AI}$ using extended and chilled semen are only slightly below those achieved by natural mating [3]. Furthermore, AI technology has now been incorporated in state government koala management policy [5]. In only one other marsupial species, the tammar wallaby, Macropus eugenii, have live births been achieved after AI [6]. Hormone-induced superovulation and AI have been successfully used as a basic research tool, and in development of fertility control vaccines for the tammar wallaby and common brushtail possum, Trichosurus vulpecula using fresh [7], and in the case of brushtail possum, frozen-thawed sperm [8]. However, in these studies, fertilisation or cleaving embryos, not full term development, has been the endpoint [9-12], and these embryos failed to develop beyond the unilaminar blastocyst stage in the hormonally manipulated females [13]. Other than these three species, the literature on AI or conventional ART for marsupials is very limited.

The koala and tammar wallaby studies have thus far only involved zoo-based or captive colony bred animals. The captive husbandry of the koala is well established [14], and the reproductive biology of the tammar wallaby is one of the best studied for any marsupial (for review see [15]). Arguably the koala and tammar wallaby are special cases, because the timing of ovulation can be predicted with considerably more confidence than in any other marsupial. The koala is an induced ovulator and techniques to artificially induce ovulation have been successfully developed $[3,4,14,16-18]$ and the tammar has a highly predictable post-partum estrus, which can be tightly synchronized by removing pouch young, and a well-defined window of ovulation [19-21]. In a limited number of other marsupials, such precise timing of ovulation has only been achieved using hormonal treatment, which is likely to have undesirable effects.

Many of the challenges facing AI and ART for marsupial conservation or animal welfare outcomes are shared with other wild species; nevertheless, marsupials also offer unique challenges and opportunities. For the vast majority of marsupials, there is a dearth of knowledge regarding female reproductive anatomy, the endocrinology of estrus, and the dynamics of sperm transport and ovulation to guide an AI strategy. For threatened or endangered species, only the most basic reproductive information is available in most cases, if at all. This highlights the importance of developing new techniques on closely related non-endangered analogue species [22]. However, there is a unique marsupial ART strategy which has been shown to have consider- able promise; this is the transfer of pouch young of threatened species to the pouches of foster mothers of a common species as a means to increase productivity [23]. Recently, cross fostering has been adopted by some wildlife agencies and zoos in Australia as tools for the conservation and management, of captive and wild macropodoid marsupials (e.g. [24]).

\section{Current status of knowledge}

\subsection{Collection and handling of semen}

Semen collection by electroejaculation (EEJ) has been established in several macropodids (tammar wallaby, yellow-footed rock wallaby, Matchie's tree kangaroo, eastern and western grey kangaroos), plus the common wombat, southern-hairy-nosed wombat, koala and common brushtail and ring-tailed possum [25-31]. Electroejaculation has allowed for the assessment of seasonal changes in semen quality observed in at least three marsupials: the tammar wallaby [32], southern hairy-nosed wombat [33], and koala (Allen et al., unpublished). Semen collection by electroejaculation has also recently become possible in the grey shorttailed opossum (Monodelphis domestica; Paris et al., unpublished) but is still sub-optimal.

The electroejaculation of dasyurid marsupials (Australian carnivores and insectivores) appears particularly problematic. For example, there have been a number of attempts to electroejaculate the largest of all dasyurids, the Tasmanian devil (Sarcophilus harrisi) [22]; although spermatozoa have been collected, the ejaculate was of limited volume or contaminated with urine and the sperm concentration low (Johnston and Blyde, unpublished observations). Semen collection by electroejaculation in the majority of dasyurids is likely to be even more difficult, given their small size $(20-50 \mathrm{~g})$ and as many have a highly acute seasonal production of spermatozoa. However, small diameter rectal probes have been constructed and used with partial success in other small marsupials (e.g. $100 \mathrm{~g}$ grey short-tailed opossum; Paris et al., unpublished) and $60 \mathrm{~g}$ phascogale (Taggart, unpublished observation) and may be applicable to small dasyurids. Conversely, natural breeding is well established for several small dasyurids in captivity (reviewed in [34]) and thus AI may not be a high priority for this group.

However, radiographic examination of the male tracts of animals infused with radiopaque dye into the vas deferens has been a useful approach to better understanding of electroejaculation in other marsupials, including the tammar wallaby [35] and such an approach 
could be useful for electroejaculation development for AI in threatened dasyurids such as the Tasmanian devil and northern quoll.

The only currently reliable means of collecting sperm from dasyurid marsupials is by epididymal dissection. Unfortunately, sperm from the cauda epididymis of dasyurids have relatively poor motility (percentage motile and character of the progressive motility) compared with macropods, brushtail possum, common wombat and the koala [36-38] and have a relatively short survival time in vitro (approximately 3 d at $4{ }^{\circ} \mathrm{C}$ Middleton, Czarny and Harris, unpublished observation).

The koala remains the only marsupial in which semen has been successfully collected with an artificial vagina (AV) [39]. It is difficult to imagine many other marsupials would be suitable for this approach.

\subsection{Sperm freezing and low temperature extension}

Interestingly, for all marsupials so far examined, the spermatozoa do not appear to exhibit a susceptibility to cold shock (brushtail possum, tammar wallaby, koala, eastern grey kangaroo and common wombat) [40]. As a result, marsupial sperm cryopreservation diluents do not necessarily require the addition of egg yolk, but they do require a high concentration of glycerol (koala 14\%; common wombat $14 \%$; southern hairy-nosed-wombat 6 $8 \%$; brushtail possum $17.5 \%$; eastern grey kangaroo 20\%; ring-tailed possum 6-8\%; northern brown bandicoot 6-8\%' long footed potoroo 6-8\%) in order to obtain reasonable levels of post-thaw survival [22]. Recently, Zee et al. [41] have suggested the use of dimethyl amide as an alternative to glycerol for the cryopreservation of koala sperm (50\% post-thaw motility). Molinia and Rodger [42] reported that a combination of glycerol (7.5\%) and DMSO (10\%) produced some (10\%) survival of tammar wallaby spermatozoa after thawing and washing by centrifugation. However, progressive motility of the motile sperm was high ( 3 on a scale of $0-5$ ) and it is possible that these sperm could be used for surgical insemination in the upper uterus or oviduct close to the time of ovulation. At the other extreme, the cryopreservation success of wombat spermatozoa is remarkable; sometimes reaching as high as $90 \%$ post-thaw motility $[29,43]$. In the possum $50-70 \%$ post-thaw motility was achieved $[42,44]$ and thawed sperm used to achieve fertile conceptions following AI into the uterus [8] and vagina (Molinia, Myers and Rodger, unpublished). The most common way of cryopreserving marsupial semen is in straws that are frozen in liquid nitrogen vapour [29] or in a programmable freezer $[41,43]$. Some studies have also been successful using a pelleting technique on dry ice $[8,37,42]$.

The most appropriate rate of freezing for marsupial spermatozoa appears to be species dependent. Most studies have used relatively rapid freezing techniques. Johnston et al. [43] conducted the only study to directly compare freezing rates and the percentage of glycerol. They reported that koala sperm frozen in a higher glycerol concentration (14\% compared to $8 \%$ ) and a slower rate $\left(6^{\circ} \mathrm{C} / \mathrm{min}\right.$ compared to rapid liquid nitrogen vapour: $3 \mathrm{~cm}$ above the liquid nitrogen surface) resulted in higher post-thaw survival. A similar but less significant effect was found in the cryopreservation of common wombat spermatozoa [43].

Koala spermatozoa also appear to be able to tolerate in vitro conditions extremely well and have been known to survive at $5{ }^{\circ} \mathrm{C}$ for upwards of $42 \mathrm{~d}$ in Tris-citrate buffer [45]. Koala sperm stored for $3 \mathrm{~d}$ at $4{ }^{\circ} \mathrm{C}$ has also been used for successful AI [3]. McCallum and Johnston [37] have also reported the successful storage of common wombat spermatozoa in the cauda epididymis. After storage for $3 \mathrm{~d}$, the sperm were dissected out of the cauda epididymis and still had a motility of approximately $60 \%$. These sperm were then cryopreserved and the resultant post-thaw motility was approximately $50 \%$.

Studies specifically relating to abnormal sperm morphology in marsupials are rare, although Johnston et al. [26] did develop a spermatogram for the koala in which the incidence of various tail abnormalities were described; a range of sperm head morphologies have also been noted in the koala, and also wombatid marsupials [31]. The significance of the various sperm heads with respect to fertilising potential remains to be investigated. Recently, Johnston et al. [46] developed a test to assess the quality of sperm DNA in koala; studies on common wombat, eastern grey kangaroo, ring-tailed possum will soon follow.

A problem with the cryopreservation of koala spermatozoa is that post-thaw survival is compromised very quickly once the sperm has been thawed and incubated at $35^{\circ} \mathrm{C}$. Most concerning is the loss of nuclear integrity that is characterised by a relaxation (swelling) of the chromatin, presumably resulting in a loss of fertility $[43,46]$. Prevention of chromatin damage will need to be solved if marsupial cryobanking is to be a viable option and is currently the topic of a number of studies, which have investigated the relationship between DNA fragmentation and the relaxation of the chromatin [41,46]. The results of these studies have shown that, whereas a small number of koalas do suffer from sperm DNA fragmentation 
(double stranded breaks of DNA), chromatin relaxation is not directly related to this phenomenon. Chromatin relaxation is more likely to be associated with the lack of cysteine residues in the marsupial protamines and the presence of basic sites in the chromatin used in the packing of sperm DNA of the koala (Johnston and Gosalvez, unpublished observations).

The cryopreservation of macropod spermatozoa has been a major challenge and little has improved since the early studies of Molinia and Rodger [42]. A major advance in this area came with the use of the cryomicroscope and fluorescent molecular probes to assess membrane integrity used these techniques to discover that kangaroo sperm frozen in $20 \%$ glycerol and a rate of $10{ }^{\circ} \mathrm{C} / \mathrm{min}$ could maintain a post-thaw motility of $70 \%$, as long as the sperm were not warmed above $20{ }^{\circ} \mathrm{C}$. Warming the sperm above this temperature quickly compromised the integrity of the plasma membrane [47-51].

\subsection{Estrus detection and female synchronization}

As discussed earlier, a contributing factor to the success of AI in the koala is that ovulation can be induced relatively simply $[3,4,18]$. By contrast, although ovulation cannot be induced by such manipulation in the tammar wallaby, birth and postpartum estrus can be tightly synchronized by removal of pouch young and ovulation is reasonably predictable, thus facilitating successful AI [6]. In animals in which the exact time of birth was not observed (making the time of ovulation less predictable), relatively simple refinements such as noting the skin colour of the newborn pouch young as it changed from bright to dull red then pink, further improved the timing of AI by up to $7 \mathrm{~h}$ [6]. In the grey short-tailed opossum, it has been known for some time that exposure to male pheromones in urine induces female breeding activity [52-54].

\subsection{Sperm in the female tract}

The dynamics and timing of sperm transport and ovulation is known for several marsupial species (tammar wallaby, Virginian opossum, brown antechinus, fat-tailed dunnart, brushtail possum and grey short-tailed opossum) $[10,20,54-62]$. This information informs decisions on the time, site and number of sperm to artificially inseminate. It should be noted, however, sperm dynamics can still differ between natural and artificial inseminates, for example, sperm numbers in the utero-oviducts are rapidly depleted $6 \mathrm{~h}$ post IU-AI, compared to sperm populations following natural mating [6,62]. In dasyurid and didelphid marsupials there is good evidence of short (hours) and long term (days) sperm storage in morphologically distinct oviductal crypts (see below). In the two other marsupials examined in some detail (brushtail possum and tammar wallaby), there is no evidence of significant short term sperm storage in either the highly secretory anterior vaginal region adjacent to the cervices or the existence of specialised crypts in the oviducts $[10,62,63]$.

Dasyurid and didelphid marsupials ejaculate relatively small numbers of sperm which are either very large (dasyurids) or paired (didelphids) [64]. In both cases, despite the relatively small number of sperm deposited by the male, the proportion of these transported to the oviducts is unusually high, with efficiencies that range from 1 in 1 or 1 in 7 ejaculated sperm reaching the site of fertilisation for brown antechinus, to 1 in 300 for grey short-tailed opossum $[54,65]$. This compares to the brushtail possum and tammar wallaby, and indeed most eutherian mammals, which are less 'efficient' (e.g. tammar wallaby 1 in 7000) [20]. Thus, inseminating low numbers of sperm in the urogenital sinus (UGS) of dasyurids/didelphids should be more efficient than inseminating millions of sperm at the same site in a tammar wallaby. Marsupial sperm are confronted with a relatively high viscosity environment in the female reproductive tract $[61,63,66,67]$. In this environment, sperm from several marsupial families (Dasyuridae, Peramelidae and Macropodidae) have been observed moving rapidly in a sinusoidal manner across surfaces, much like a snake, rather than swimming per se, or in the Didelphidae, as sperm pairs with superior motility over single sperm $[28,38,67,68]$. These unique sperm movement modes may explain the high migration efficiency observed in dasyurid and didelphid marsupials.

Prolonged sperm storage in oviductal crypts, and the apparent long time for sperm capacitation, in some dasyurid and peramelid marsupials, however, may make timing of AI problematic in these species [58,69-72]. Natural mating studies in brown antechinus [58] have demonstrated optimal fertility when mating occurs $\sim 9.5 \mathrm{~d}$ before ovulation, but reduced fertility when sperm reside in the female tract $<5$ or $>13 \mathrm{~d}$. Conversely, this might prove useful as it provides a broad time window over which AI could be performed, if inseminated sperm can survive in vivo for a sufficient number of days.

\subsection{Site of insemination}

An understanding of the anatomy of the marsupial female reproductive tract is essential to a discussion of 

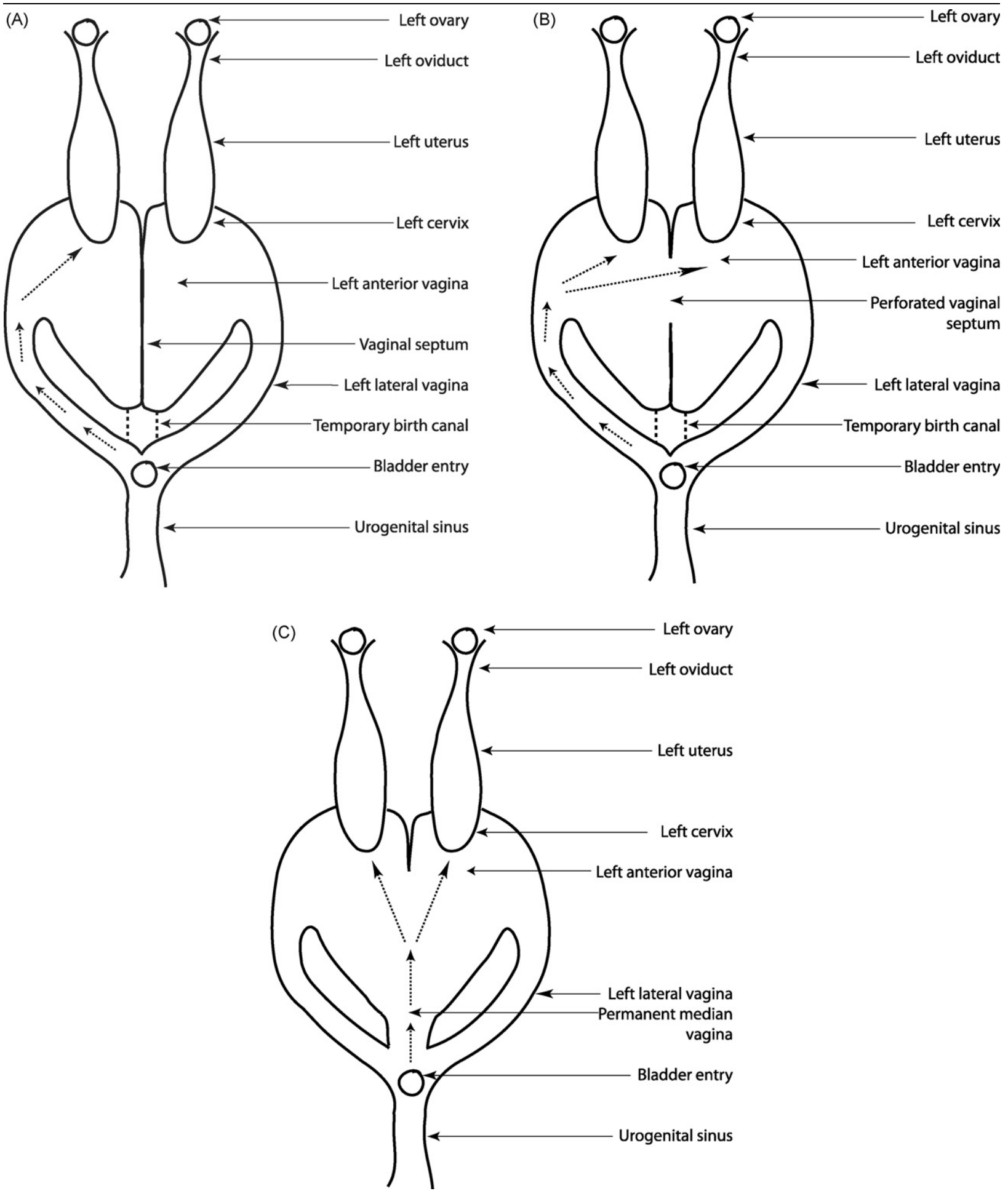

Fig. 1. Stylized marsupial female reproductive tracts, showing the path of natural insemination (dashed lines with arrow heads); (A) prior to first parturition in all marsupials, where the two sides of the female tract are completely separate (path via right side only shown), (B) in subsequent matings in those species, where the vaginal septum is perforated at first parturition, allowing sperm from either side of the vagina to access both cervices and, (C) in those species where a permanent median vagina is formed after the first parturition, allowing direct access from the urogenital sinus to the cervices. 
AI, because it greatly restricts access to the cervices, the primary target for AI in most eutherian mammals (Fig. 1). Although the detailed anatomy of the vaginal complex differs between marsupial groups, there are common features based on embryology which pose challenges for AI. The opening to the exterior which is easily accessible is to the common UGS which is the site of penile penetration, female urine flow and the birth passage. At its anterior end, the UGS communicates with the bladder and two relatively narrow openings to separate lateral vaginae which in many marsupials expand out to form large and separate saclike pouches into which the natural ejaculate is received. Presumably, semen ejaculated into the UGS is moved up to the anterior vaginae by mating-induced contractions of the muscular lateral vaginae. In macropodid marsupials, however, the viscous ejaculate is deposited directly into the permanent median vagina, where semen rapidly fills the highly secretory anterior vagina [20], adjacent to the cervices [63]. Despite the great variability in vaginal anatomy in all marsupials, uterine and oviduct anatomy is remarkably similar. All have completely separate left and right side systems, each with its own cervix. In most marsupials, the fimbriated end of the oviduct is open to the peritoneum except in, at least, the koala and wombat where the oviduct forms a bursa which encloses the ovary $[73,74]$. Birth in marsupials is not via the lateral vaginae, but by a transient birth canal which appears at the time of parturition between the central section of the vaginal complex and the underlying UGS. In most marsupials (with the exception of macropodids and wombats) this structure breaks down and normal anatomy is reestablished after parturition. Commonly after parturition, the two sides of the lateral vaginae do communicate via the perforated central wall between them, creating a common vaginal system. In macropods (kangaroos and wallabies) after the first parturition, the birth canal persists as a median 'third' vaginal canal and a relatively direct route for AI. In all studies thus far, AI has been either via the UGS (koala, tammar), vagina (tammar, possum) or uterus (tammar, possum).

Sperm transport and ovulation do not appear to be affected by anaesthesia after AI to the urogenital sinus (UGS-AI) or uterus (IU-AI) in the brushtail possum or tammar wallaby $[6,9,10]$ or vaginal $\mathrm{AI}$ in brushtail possum $[9,13]$. While it is tempting to suggest that the relative success of UGS-AI in the koala could be partly explained by the absence of anaesthesia, koala joeys have also been born following deposition of semen directly into the lateral vaginal ostia in anaesthetised koalas [4]. In addition, IU-AI immedi- ately post-ovulation would not offer a viable option in marsupials due to the narrow window of fertilisation, limited by rapid mucin deposition around the oocyte. In all marsupials, an oviduct secreted mucin layer is deposited on the surface of the zona pellucida, preventing sperm access. That this occurs at around the time of fertilisation, it may be component of the block to polyspermy in marsupials [56].

As discussed above, the female vaginal anatomy of marsupials is highly variable among species [75]. An understanding of this anatomy is crucial if non-surgical insemination by catheter is to be utilized. Artificial insemination catheter dye studies in tammar, southern hairy-nosed wombat (Lasiorhinus latifrons) and the grey short-tailed opossum (M. domestica) have been undertaken to determine the effectiveness of this method of insemination [76,77]. In the polyovular opossum, only UGS-AI by catheter is feasible due to convoluted lateral vaginae and the absence of a median vagina. However, sperm can traverse the incomplete septum that divides each cervix and thereby fertilize oocytes on both sides of the tract. In the monovular wombats and koala, the vaginal septum prevents semen from either side reaching the contralateral cervix. In the monovular post-partum tammar wallaby by contrast, there is no septum and the median vagina provides direct access to both cervices permitting insemination by catheter.

\section{Advantages and applications}

Artificial insemination and other ART potentially offer an essentially similar set of tools to assist in conservation breeding programs for a range of vertebrates. This is especially true if the gametes can be stored indefinitely, because it then facilitates the long term use of this material for genetic management and the maximisation of genetic diversity in the future [22]. One of the most immediate advantages of assisted breeding and $\mathrm{AI}$ is that, as in agriculture, it can essentially eliminate the need to transport live animals for breeding programs, either nationally or internationally. For highly iconic species, like the koala, this is an important issue and underpins the research to date of Johnston and his colleagues in Queensland (e.g. [3]). In field situations, AI-ART offers a potentially highly effective method to manage genetic diversity in fragmented populations without translocation of animals with its inherent risks (e.g. rock wallabies). Furthermore, AI and ART have the advantage of offering the screening of disease free gametes or embryos for use in species such as the koala (e.g. Chlamydia [78,79]) and Tasmanian devil, where disease is a major threatening process. 
As discussed briefly, there is a uniquely marsupial approach to ART, termed cross fostering, which has shown considerable promise. It has been applied to enhance the reproductive rate and productivity of young of threatened species from the marsupial families Macropodidae and Potoroidae [23,80-84]. This approach makes use of the long established principle that small pouch young, as early as day 1 of pouch life, can be transferred to the pouch of an appropriately prepared surrogate mother where normal development to pouch emergence occurs $[15,83,85]$. Using this approach, pouch young have been harvested in the field from rock wallabies and potoroos, transported cooled to a captive colony of a closely related surrogate species and then the young re-attached to timed nipples in the pouches of surrogate mothers $[23,83,84]$. There are questions over the subsequent social training and behaviour of these animals, but evidence to date is that these animals do not show gross behavioural abnormalities, but readily recognize and mate with their own species provided once weaned, they are housed with their own kind $[23,80,83,85]$. Cross fostering can potentially increase the production of young of the threatened species by $2-8$-fold $[23,80,83]$. This unique form of surrogacy allows harvesting of young animals from captive or free ranging populations, the mother's of which would subsequently return to estrus and breed again. The cross fostered young being either returned to their site of origin, or used in reintroduction programs. The process is elegant and simple and it optimises the unique reproductive biology of the marsupial without any need for more highly invasive or technically complex procedures. This technology is obviously also relevant to subsequent discussions of induced superovulation and the production of multiple young in normally monovular species, and arguably, may be a more generally applicable method than AI for marsupials. This said, cross fostering can raise ethical concerns, because a pouch young must be removed and euthanased to provide the teat for the cross fostered young. However, this is balanced by the potential benefits of enhancing the breeding potential and conservation outcomes for threatened marsupial fauna. In addition, removal and euthanasia of small and undeveloped 'embryo-like' pouch young (RPY) is a well established reproductive management tool to reactivate cycling in marsupials.

Artificial insemination and other ART will find continuing use as a research tool in situations like the screening of fertility control vaccines/agents as a means of non-lethal population control for the introduced brushtail possum in New Zealand and in areas with local overabundance of macropods in many regions of Australia and the Koala in Victoria and South Australia $[11,86]$. Also, with the growing importance of grey short-tailed opossum as a biomedical model and the availability of its genome [87], it is likely AI and other ART will be required to generate, cryo-bank, and reintroduce mutant/transgenic opossum strains in captive research colonies.

\section{Complications and problems}

\subsection{Semen collection and preservation}

Electroejaculation, which is the method of choice in most non-tractable wild animals, is not available for all marsupial groups. In the grey short-tailed opossum, EEJ is still sub-optimal compared to natural ejaculates (1000-fold less sperm with reduced progressive motility; Paris et al., unpublished). There are currently no protocols for the electroejaculation of dasyurids, but substantial research is being applied to electroejaculation in the highly threatened Tasmanian devil [88]. Although reasonable post-thaw viability and motility has been achieved for cryopreserved sperm of several marsupials, there are a number of examples in which the extensive application of AI as a conservation management tool is impeded by poor cryopreservation outcomes, including dasyurids and most macropodids.

\subsection{Effects of hormone treatments on embryo production and development}

Hormone-induced ovarian cycles and superovulation are well established features of assisted reproduction in domestic species and humans, especially when linked with conventional IVF or intra-cytoplasmic sperm injection (ICSI) to produce embryos for transfer. The normality of embryos produced by exogenous hormone treatment/AI in marsupials has yet to be established, but they do not develop to term in stimulated and then inseminated brushtail possums [13]. However, in the tammar wallaby, normal mating and development to blastocyst stage has occurred in females stimulated with FSH and LH [89]. In the dunnart, mating, late stage embryos and full term development occurs after treatment with eCG $[90,91]$. Thus, whatever the limitation of such oocytes and the female tract environment, normal development is not precluded, at least in polyovular species.

Although Magarey et al. [92] demonstrated normal fertility among superovulated tammar wallabies follow- 
ing natural mating in subsequent cycles, it is still not clear to what extent monovular marsupials can produce offspring during superovulated cycles. Live birth is also complicated by the fact that most target species for superovulation have been monovular and may be incapable of carrying multiple 'super-ovulated' pregnancies to term. That said, twinning does occur in monovular marsupials and such superovulated females could be the source of embryos for transfer to the uteri of synchronized surrogates. As in all marsupials, the number of available teats will set the absolute limit on the number of neonates that could survive in the pouch. However, as discussed earlier, transfer of young to the pouches of surrogates for their full growth and development is feasible, based on the success of cross fostering.

Alternative strategies for ovulation induction (e.g. removal of suckling pouch young (RPY) and pairing) are still in general not sufficiently precise for timing of AI. Except for relatively predictable species such as the tammar wallaby and grey short-tailed opossum, for the majority of marsupials, timing of the return to estrus after RPY ranges over several days [75]. Perhaps in these species, RPY could be combined with ultrasonography, in those marsupials where preovulatory follicles are large enough to detect, and/or LH injection to refine the time of ovulation. For example, in a study on naturally cycling brushtail possums induced by removal of pouch young (RPY), LH treatment caused $70 \%$ of animals to ovulate, compared with $40 \%$ that were not LH treated (Molinia, unpublished observation). However, frequent handling to improve accuracy of predicted ovulation, can delay the time of estrus in the tammar wallaby [20]. In addition, due to the acquisition of oviduct secreted mucin layers (impenetrable to sperm) around the oocyte during rapid transport to the uterus, the window for fertilisation is extremely brief for most spontaneously ovulating marsupials, making the window of opportunity for AI narrow.

Vaginal cytology could be an alternative strategy to monitor natural cyclicity and determine the time of estrus for $\mathrm{AI}$, and has been reported in several marsupials [52,93,94]. However, this does not overcome the previously mentioned problems associated with frequent animal handling, nor provide a level of accuracy sufficient for the narrow window of insemination. Urogenital sinus smears tend to be a retrospective indicator of ovulation (appearance of white blood cells) in relatively long estrus cycles and thus are not generally likely to be useful for AI timing in most marsupials.

\section{Future research priorities}

\subsection{Is the koala a special case?}

One of the key observations in marsupial AI is that most marsupials do not behave like koalas and koalas do not behave like most marsupials. Why are there such striking differences between the efficient and reproducible AI success in koalas compared with those marsupials (such as the tammar and possum) that have received equal if not more research effort in this area? Even in wombats (the closest relatives of koalas), AI has been unsuccessful [95], despite numerous recent publications about wombat reproductive physiology [94,96-101]. Future research will need to address this fundamental question, if $\mathrm{AI}$ is to have a significant impact in other marsupial species. There are several obvious differences in reproductive physiology that might partly explain this including: an overt, prolonged estrus (up to $10 \mathrm{~d}$ ), as well as induced ovulation triggered by coitus and seminal factors in the koala. This compares with a relatively short estrus $(<1 \mathrm{~d})$, plus a spontaneous and variable ovulation time followed by a narrow window for fertilisation in most other well studied marsupials. It should be noted that all substantial developments in AI of the three main species of marsupial (koala, tammar and possum) have been the result of access to relatively large numbers of individuals in captivity in either research colonies or zoos.

\subsection{Appropriate or inappropriate target species for} AI

It is difficult to assess which species are appropriate/ inappropriate for AI. However, as a starting point, appropriate species might include those that would: (i) have the greatest likelihood of success from this procedure, or (ii) have an increasing need to help manage genetics or improve its decreasing natural fertility. The endangered brush-tailed rock wallaby and northern hairy-nosed wombat may be two such candidates. Of course, there are some species that are so critically endangered (e.g. the highly stress-prone Gilbert's potoroo) that one might suggest are inappropriate for AI because the associated risks and inefficiencies do not justify the method. In these instances, effort may be better focussed on (semi)captive breeding in highly protected environments.

\subsection{Synchronization of female reproductive activity}

Relatively simple endocrinologically based systems to synchronize ovarian function to optimise oocyte 
collection for IVF/ICSI or AI are well established features of assisted breeding for humans and domestic animals. No such system has been developed for marsupials, except the observation that lactating females (possums, wallabies), which are naturally suppressed, are good subjects for exogenous hormone stimulation $[9,12,102]$. A feature of marsupial ovarian cycles is the fact that the CL is maintained independent of pregnancy hormones (reviewed in [15]). Thus, simple manipulations which effectively induce luteolysis in eutherian species have no effect in marsupials. As discussed, removal of suckling young will reactivate natural cycles, but even when this would be a useful ART and not counter productive, the timing of return to ovulation is generally very imprecise and ranges over several days.

Although there has been considerable interest, and success, in the use of long acting GnRH agonists and steroid implants to suppress ovarian activity in marsupials (e.g. tammar, koala, possum [103,104]). This approach has, perhaps surprisingly, only recently been applied to sychronization for AI, but preliminary studies on the use of such a compound to manipulate anterior pituitary function in male koalas was not effective at the dose rates used [16]. A reasonably generic strategy to synchronize female marsupial reproductive activity is arguably the most critical factor limiting the broader application of ART to marsupials for research or conservation. This is true whether the approach is for AI, oocyte donors, embryo donors, or embryo recipients. Based on current practice and developments in eutherian species, and the demonstrated effectiveness of the GnRH agonist (deslorelin/suprolelin) in female marsupials [103], this would seem a very high priority for research.

\subsection{Emerging potentially generic technologies for broad taxon application}

As just discussed, female synchronization is a major problem for marsupials that needs to be addressed, but ICSI in marsupials (tammar wallaby and common wombat) by contrast appears relatively generic $[101,105,106]$. Sperm injection is now so well established for treatment of human infertility that several million babies have been produced and in some countries, it now is the preferred method of IVF. Despite the apparent high-tech and manipulative character of this technology, in the hands of experienced technicians, it can be expected to be eventually applicable to a wide range of species. In addition, ICSI potentially overcomes many issues of spermatology (e.g. sperm numbers, sperm motility, sperm cryopreservation, sperm capacitation and the short fertilisation window due to mucoid). It should be noted, however, that embryo development after ICSI did not progress beyond the 8-cell stage at best in these marsupials, and the track record of this technology in wildlife to date, measured by the number of offspring produced, is poor by comparison to AI [107]. That said, ICSI is likely in the longer term to make an important contribution to marsupial assisted reproduction and bypass many of the current challenges faced by AI. In addition, ICSI has the potential to use freeze-dried or cadaver material as a source of sperm or spermatids for ART, as this has now been achieved in rabbits as well as mice $[108,109]$. Despite the highly manipulative character of such approaches, there is growing evidence of the normality of such offspring [110]. Almost certainly, tertiary egg coats (mucin and shell) will be required for subsequent development of ICSI-produced marsupial embryos, but such should not be an unachievable goal if effectively synchronized fertilized egg or embryo recipients are available for oviductal or uterine transfer.

There remains a caveat over the potential of freeze drying, or even conventional freezing approaches, for marsupial sperm $[41,46]$. The sperm of all marsupials, but one sub-group of dasyurids the planigales, lack disulphide-stabilized protamines in the sperm chromatin [111]. In the mouse, the degree of disulphide stabilization, which increases as sperm pass down the epididymis, is correlated with success in using freezedried sperm heads for ICSI [112]. However, despite this, the heads of the fat-tailed dunnart sperm (a dasyurid lacking protamines) remain intact with apparently normal morphology after being freeze-dried [113]. Whether, such sperm can be used for ICSI has yet to be tested, but it suggests that marsupial sperm heads have a degree of stabilization despite the lack of protamines. Further studies of DNA damage of marsupial sperm following manipulation, cold storage or freezing, are required to better understand the potential risks posed.

\subsection{Cross fostering and pouch young transfer}

Data on cross fostering is now available for 4 potoroid and 13 macropodid species, with success varying widely from complete failure to an 8-fold increase in the production of pouch young (PY) annually [83]. Factors implicated in successful cross fostering include; relative size of donor and host females, size of PY at weaning, differences in length of pouch life between species and size differences between donor and surrogate young at transfer. Studies have shown that females regulate milk 
composition and production irrespective of PY age and that transfer to species with teats of more immature or advanced staged mammary glands, will result in either a slowing or acceleration of pouch young growth/development [23]. The relationship between milk (composition, hormones and volume), pouch young growth rate and cross fostering success requires further investigation. Thus far, this approach has only been applied to macropods and its applicability to marsupials more generally needs to be examined.

\section{Conclusions}

If AI, and assisted reproduction more generally, are to become widely used technologies for marsupial conservation, then there must be more generic approaches which depend less on detailed knowledge of the species reproductive biology generally and gamete biology specifically. Except for a few, usually highly iconic species such as the koala, or well studied species (e.g. tammar wallaby, brushtail possum, gray short-tailed opossum), there is unlikely to ever be sufficient basic reproductive information on which to base AI in the foreseeable future. Whatever approach is taken synchronization of the female for AI, ET or oocyte donation will be the major technical challenge. However, if technologies such as ICSI (to generate embryos) and female synchronization (to provide recipients) can be developed for marsupials then the prospects for broader application of AI/ART are promising. If not, then the next $30 \mathrm{y}$ of research is unlikely to yield profoundly more practical outcomes than the previous 30 , except for cooperative or high profile species. This would include the iconic koala, and its near relative, the critically endangered northern hairy-nosed wombat, and model species like the gray short-tailed opossum and tammar wallaby. Progress on ART for the common brushtail possum is also likely to continue, because of the major focus on this species as an introduced pest of major significance in New Zealand. However, a major constraint will remain the level and long term certainty of funding for research and the maintenance of laboratory colonies of model marsupials. If only a small fraction of the resources that have been used to develop AI/ART for humans and domestic animals in Australia were committed to AI/ART for marsupial conservation outcomes, then much more progress would have, and will be made.

\section{Acknowledgements}

This paper is the result of a very friendly collaboration of researchers with diverse views and experience of marsupial AI and represents a broad consensus. The final selection of topics to include or exclude is the responsibility of the first author. The work of J.C.R., M.H. and F.M. was supported by the Australian Governments Cooperative Research Centres Program, the Australian Research Council and the New Zealand Ministry of Agriculture and Forestry. D.P. was funded by a European Commission Marie Curie Incoming International Fellowship. S.J. and C.A. thank their essential collaborators at Lone Pine Koala Sanctuary, Currumbin Wildlife Sanctuary, and Dreamworld. We all acknowledge the many research colleagues and collaborators who have been invaluable in our efforts to develop and apply AI and ART to marsupials.

\section{References}

[1] Rodger JC, White IG. The collection, handling and some properties of marsupial semen. Symp Zool Soc Lond 1978;43: 289-301.

[2] Watson PF. Artificial breeding of non-domestic animals. London: Academic Press; 1978.

[3] Allen CD, Burridge M, Mulhall S, Chafer ML, Nicolson VN, Pyne M, et al. Successful artificial insemination in the koala (Phascolarctos cinereus) using extended and extended-chilled semen collected by electroejaculation. Biol Reprod 2008;78: 661-6.

[4] Johnston SD, McGowan M, O'Callaghan P, Cox R, Houlden B, Haig S, et al. Birth of koala, Phascolarctos cinereus, at Lone Pine Koala Sanctuary following artificial insemination. Int Zoo Yearbk 2003;38:160-72.

[5] Environmental Protection Authority. Nature conservation (koala) conservation plan 2006 and management program; 2006.

[6] Paris DBBP, Taggart DA, Shaw G, Temple-Smith PD, Renfree MB. Birth of pouch young after artificial insemination in the tammar wallaby (Macropus eugenii). Biol Reprod 2005;72: 451-9.

[7] Molinia FC, Glazier AM, Myers JV, Sidhu KS, Mate KE, Berg $\mathrm{DK}$, et al. In vitro and in vivo models of key reproductive events as tools for possum biological control, biological management of possums. Wellington, New Zealand: Ministry of Agriculture and Forestry; 2001.

[8] Molinia FC, Myers JV. Fertility of frozen-thawed possum spermatozoa after laparoscopic artificial insemination. In: Proceedings of the 30th Annual Conference of the Australian Society for Reproductive Biology; 1999.

[9] Glazier AM, Molinia FC. Development of a porcine folliclestimulating hormone and porcine luteinizing hormone induced ovulation protocol in the seasonally anoestrus brushtailed possum. Reprod Fertil Dev 2002;14:453-60.

[10] Jungnickel MK, Molinia FC, Harman AJ, Rodger JC. Sperm transport in the female reproductive tract of the brushtail possum, Trichosurus vulpecula, following superovulation and artificial insemination. Anim Reprod Sci 2000;59:213-28.

[11] Kitchener AL, Edds LM, Molinia FC, Kay DJ. Porcine zonae pellucidae immunisation of tammar wallabies (Macropus eugenii): fertility and immune responses. Reprod Fertil Dev 2002;14: 215-23. 
[12] Molinia FC, Gibson RJ, Brown AM, Glazier AM, Rodger JC. Successful fertilization after superovulation and laparoscopic intrauterine insemination of the brushtailed possum, Trichosurus vulpecula, and tammar wallaby, Macropus eugenii. J Reprod Fertil 1998;113:9-17.

[13] Molinia FC, Myers JV, Glazier AM, Duckworth JA. Uterine and vaginal insemination optimised in brushtail possums (Trichosurus vulpecula) superovulated with pregnant mare serum gonadotrophin and porcine luteinising hormone. Reprod Fertil Dev 2007;19:521-9.

[14] Johnston SD, McGowan MR, O'Callaghan P, Cox R, Nicolson V. Studies of the oestrous cycle, oestrus and pregnancy in the koala (Phascolarctos cinereus). J Reprod Fertil 2000;120:49-57.

[15] Tyndale-Biscoe H. Life of mrsupials. Collingwood, Australia: CSIRO publishing; 2005.

[16] Allen CD, Burridge M, Chafer ML, Nicolson VN, Jago SC, Booth RJ, et al. Control of the koala (Phascolarctos cinereus) anterior pituitary-gonadal axis with analogues of GnRH. Reprod Fertil Dev 2008;20:598-605.

[17] Johnston SD, McGowan MR, O’Callaghan P, Cox R, Nicolson V. Natural and artificial methods for inducing the luteal phase in the koala (Phascolarctos cinereus). J Reprod Fertil 2000;120: 59-64.

[18] Johnston SD, O'Callaghan P, Nilsson K, Tzipori G, Curlewis JD. Semen-induced luteal phase and identification of a $\mathrm{LH}$ surge in the koala (Phascolarctos cinereus). Reproduction 2004;128:629-34.

[19] Merchant JC. The effect of pregnancy on the interval between one oestrus and the next in the tammar wallaby, Macropus eugenii. J Reprod Fertil 1979;56:459-63.

[20] Paris DBBP, Taggart DA, Paris MCJ, Temple-Smith PD, Renfree MB. Sperm transport, size of the seminal plug and the timing of ovulation after natural mating in the female tammar wallaby Macropus eugenii. Reprod Fertil Dev 2004;16:811-22.

[21] Rudd CD. Sexual behaviour of male and female tammar wallabies (Macropus eugenii) at post-partum oestrus. J Zool 1994;232:151-62.

[22] Johnston SD, Holt WV. Germplasm conservation in marsupials. In: Watson PF, Holt WV, editors. Cryobanking the genetic resources: wildlife conservation for the future. London: Taylor \& Francis; 2001. p. 201-26.

[23] Taggart DA, Schultz DJ, White C, Whitehead P, Underwood G, Phillips K. Cross-fostering, growth and reproductive studies in the brush-tailed rock-wallaby, Petrogale penicillata (Marsupialia: Macropodidae): efforts to accelerate breeding in a threatened marsupial species. Aust J Zool 2005;53:313-23.

[24] Waldegrave-Knight L. Brush-tailed rock wallaby (Petrogale penicillata) Flora and Fauna Guarantee Action Statement (Flora and Fauna Guarantee Act 1988). Melbourne, Victoria: Department of Sustainability and Environment; 2003.

[25] Johnston SD, Blyde D, Gamble J, Higgins D, Field H, Cooper J. Collection and short-term preservation of semen from freeranging eastern grey kangaroos (Macropus giganteus: Macropodidae). Aust Vet J 1997;75:648-51.

[26] Johnston SD, McGowan MR, Carrick FN, Cameron RDA, Tribe A. Seminal characteristics and spermatozoa morphology of captive Queensland koalas. Theriogenology 1994;42:501-11.

[27] Rodger JC, White IG. Free N-acetylaminosugar in the seminal plasma of eutherian mammals. J Reprod Fertil 1975;45:379-81.

[28] Taggart DA, Leigh CM, Schultz D, Breed WG. Ultrastructure and motility of spermatozoa in macropodid and potoroidid marsupials. Reprod Fertil Dev 1995;7:1129-40.
[29] Taggart DA, Leigh CM, Steele VR, Breed WG, Temple-Smith PD, Phelan J. Effect of cooling and cryopreservation on sperm motility and morphology of several species of marsupial. Reprod Fertil Dev 1996;8:673-9.

[30] Taggart DA, Steele VR, Schultz D, Dibben R, Dibben J, Temple-Smith PD. Semen collection and cryopreservation in the southern hairy-nosed wombat Lasiorhinus latifrons: implications for conservation of the northern hairy-nosed wombat Lasiorhinus krefftii. In: Wells RT, Pridmore PA, editors. Wombats. Chipping Norton: Surrey Beatty and Sons; 1998. p. $180-91$.

[31] Wildt DE, Bush M, O’Brien SJ, Murray ND, Taylor A, Marshall Graves JA. Semen characteristics in free-living Koalas (Phascolarctos cinereus). J Reprod Fertil 1991;92:99-107.

[32] Paris DBBP, Taggart DA, Shaw G, Temple-Smith PD, Renfree MB. Changes in semen quality and morphology of the reproductive tract of the male tammar wallaby parallel seasonal breeding activity in the female. Reproduction 2005;130:36778.

[33] Taggart DA, Shimmin GA, Ratcliff RJ, Steele VR, Dibben R, Dibben J, et al. Seasonal changes in the testis, accessory glands and ejaculate characteristics of the southern hairy-nosed wombat, Lasiorhinus latifrons (Marsupialia: Vombatidae). J Zool 2005;266:95-104.

[34] Mate KE, Gentle RL, Fletcher TP, Rodger JC. Australian marsupials. In: Poole TB, editor. Universities Federation for Animal Welfare (UFAW) handbook on the care and management of laboratory animals. 7th ed., London: Blackwell Press; 1999. p. 210-34.

[35] Rodger JC, Pollitt CC. Radiographic examination of electroejaculation in marsupials. Biol Reprod 1981;24:1125-34.

[36] Czarny NA, Mate KE, Rodger JC. Acrosome stability in the spermatozoa of dasyurid marsupials. Reprod Fertil Dev 2008;20:295-302.

[37] MacCallum C, Johnston SD. Studies on the cryopreservation of common wombat (Vombatus ursinus) spermatozoa. Reprod Fertil Dev 2005;17:727-32.

[38] Taggart DA, Temple-Smith P. An unusual mode of progressive motility in spermatozoa from the dasyurid marsupial, Antechinus stuartii. Reprod Fertil Dev 1990;2:107-14.

[39] Johnston SD, O'Callaghan P, McGowan MR, Phillips NJ. Seminal characteristics of koala ejaculates collected using an artificial vagina. J Reprod Fertil 1997;109:319-23.

[40] Miller Jr RR, Sheffer CJ, Cornett CL, McClean R, MacCallum C, Johnston SD. Sperm membrane fatty acid composition in the Eastern grey kangaroo (Macropus giganteus), koala (Phascolarctos cinereus), and common wombat (Vombatus ursinus) and its relationship to cold shock injury and cryopreservation success. Cryobiology 2004;49: $137-48$.

[41] Zee Y, Holt W, Gosalvez J, Allen C, Nicolson V, Pyne M, et al. Dimethylacetamide can be used as an alternative to glycerol for the successful cryopreservation of koala (Phascolarctos cinereus) spermatozoa. Reprod Fertil Dev 2008;20:724-33.

[42] Molinia FC, Rodger JC. Pellet-freezing of two marsupials: the tammar wallaby, Macropus eugenii, and the brushtail possum, Trichosurus vulpecula. Reprod Fertil Dev 1996;8:681-4.

[43] Johnston SD, MacCallum C, Blyde D, McClean R, Lisle A, Holt WV. An investigation into the similarities and differences governing the cryopreservation success of koala (Phascolarctos cinereus: Goldfuss) and common wombat (Vombatus ursinus: Shaw) spermatozoa. Cryobiology 2006;53:218-28. 
[44] Rodger JC, Cousins SJ, Mate KE. A simple glycerol-based freezing protocol for the semen of a marsupial Trichosurus vulpecula, the common brushtail possum. Reprod Fertil Dev 1991;3:119-25.

[45] Johnston S, McGowan M, Phillips N, O'Callaghan P. Optimal physiochemical conditions for the manipulation and short-term preservation of koala (Phascolarctos cinereus) spermatozoa. J Reprod Fertil 2000;118:273-81.

[46] Johnston SD, Lopez-Fernandez C, Gosalbez A, Zee Y, Holt $\mathrm{WV}$, Allen $\mathrm{C}$, et al. The relationship between sperm morphology and chromatin integrity in the koala (Phascolarctos cinereus) as assessed by the sperm chromatin dispersion test (SCDt). J Androl 2007;28:891-9.

[47] Holt WV, Penfold LM, Johnston SD, Temple-Smith PD, McCallum C, Shaw J, et al. Cryopreservation of macropodid spermatozoa: new insights from the cryomicroscope. Reprod Fertil Dev 1999;11:345-53.

[48] McClean R. Cryopreservation of kangaroo spermatozoa. $\mathrm{PhD}$ thesis. Brisbane, Australia: The University of Queensland; 2008.

[49] McClean R, MacCallum C, Blyde D, Holt WV, Johnston L. Ultrastructure, osmotic tolerance, glycerol toxicity and cryopreservation of caput and cauda epididymal kangaroo spermatozoa. Reprod Fertil Dev 2006;18:469-76.

[50] McClean R, MacCallum C, Blyde D, Holt WV, Johnston SD. Actin localisation and the effect of cytochalasin D on the osmotic tolerance of cauda epididymidal kangaroo spermatozoa. CryoLetters 2006;27:235-60.

[51] McClean RV, Holt WV, Johnston SD. Ultrastructural observations of cryoinjury in kangaroo spermatozoa. Cryobiology 2007;54:271-80.

[52] Baggott LM, Davis-Butler S, Moore HD. Characterization of oestrus and timed collection of oocytes in the grey short-tailed opossum, Monodelphis domestica. J Reprod Fertil 1987;79: 105-14.

[53] Fadem BH, Tesoriero JV. Inhibition of testicular development and feminization of the male genitalia by neonatal estrogen treatment in a marsupial. Biol Reprod 1986;34:771-6.

[54] Paris DBBP, Paris M, Mackay S, Ullmann S, Kennedy M, Gilmore D, et al. Migration efficiency of paired sperm in the tract of the peri-ovulatory female grey short-tailed opossum (Monodelphis domestica). In: Proceedings of the 10th International Symposium on Spermatology; 2006.p. 83.

[55] Breed WG, Leigh CM, Bennett JH. Sperm morphology and storage in the female reproductive tract of the fat-tailed dunnart, Sminthopsis crassicaudata (Marsupialia: Dasyuridae). Gamete Res 1989;23:61-75.

[56] Rodger JC, Bedford JM. Induction of oestrus, recovery of gametes, and the timing of fertilization events in the opossum, Didelphis virginiana. J Reprod Fertil 1982;64:159-69.

[57] Rodger JC, Bedford JM. Separation of sperm pairs and spermegg interaction in the opossum, Didelphis virginiana. J Reprod Fertil 1982;64:171-9.

[58] Selwood L, McCallum F. Relationship between longevity of spermatozoa after insemination and the percentage of normal embryos in brown marsupial mice (Antechinus stuartii). J Reprod Fertil 1987;79:495-503.

[59] Shimmin GA, Jones M, Taggart DA, Temple-Smith PD. Sperm transport and storage in the agile antechinus (Antechinus agilis). Biol Reprod 1999;60:1353-9.

[60] Taggart DA, Shimmin GA, McCloud P, Temple-Smith PD. Timing of mating, sperm dynamics, and ovulation in a wild population of Agile Antechinus (Marsupialia: Dasyuridae). Biol Reprod 1999;60:283-9.

[61] Taggart DA, Temple-Smith P. Transport and storage of spermatozoa in the female reproductive tract of the brown marsupial mouse, Antechinus stuartii (Dasyuridae). J Reprod Fertil 1991;93:97-110.

[62] Tyndale-Biscoe CH, Rodger JC. Differential transport of spermatozoa into the two sides of the genital tract of a monovular marsupial, the tammar wallaby (Macropus eugenii). J Reprod Fertil 1978;52:37-43.

[63] Hughes RL, Rodger JC. Studies on the vaginal mucus of the marsupial Trichosurus vulpecula. Aust J Zool 1971;19:19-33.

[64] Temple-Smith PD. Comparative structure and function of marsupial spermatozoa. Reprod Fertil Dev 1994;6:421-35.

[65] Taggart DA. A comparison of sperm and embryo transport in the female reproductive tract of marsupial and eutherian mammals. Reprod Fertil Dev 1994;6:451-72.

[66] Hartman C. Observations on the motility of the opossum genital tract and the vaginal plug. Anat Rec 1924;27:293-303.

[67] Moore H, Taggart D. Sperm pairing in the opossum increases the efficiency of sperm movement in a viscous environment. Biol Reprod 1995;52:947-53.

[68] Taggart DA, Leigh CM, Breed WG. Ultrastructure and motility of spermatozoa in the male reproductive tract of peramelid marsupials. Reprod Fertil Dev 1995;7:1141-56.

[69] Foster W, Caton W, Thomas J, Cox S, Taggart DA. Timing of birth and reproductive success in captive red-tailed phascogales, Phascogale calura. J Mammal; in press.

[70] Lyne AG, Hollis DE. The early development of marsupials with special reference to the bandicoots. In: Calaby JH, TyndaleBiscoe CH, editors. Reproduction and evolution. Canberra: Australian Academy of Science; 1977. p. 293-302.

[71] Millis AL, Taggart DA, Bradley AJ, Phelan J, Temple-Smith PD. Reproductive biology of the brush-tailed phascogale, Phascogale tapoatafa (Marsupialia: Dasyuridae). J Zool 1999;248:325-35.

[72] Taggart DA, Shimmin GA, Dickman CR, Breed WG. Reproductive biology of carnivorous marsupials: clues to the likelihood of sperm competition. In: Jones ME, Dickman CR, Archer M, editors. Predators with pouches: the biology of carnivorous marsupials. Collingwood: CSIRO Publishing; 2003. p. 358-75.

[73] MacCallum C. The reproductive biology of the common wombat (Vombatus ursinus): studies towards the development of an artificial insemination protocols. In: Masters of philosophy. Brisbane, Australia: The University of Queensland; 2005.

[74] Obendorf DL. The pathogenesis of urogenital tract disease in the koala. Australian Wildlife, Proceedings Number 104. Australia: Post-Graduate Committee in Veterinary Science, University of Sydney; 1988. p. 649-55.

[75] Tyndale-Biscoe CH, Renfree M. Reproductive physiology of marsupials. Cambridge: Cambridge University Press; 1987.

[76] Paris DBBP. Reproductive anatomy of the female grey shorttailed opossum (Monodelphis domestica): considerations for developing artificial insemination by catheter. Reprod Fertil Dev 2006;18:222.

[77] Paris DBBP, Taggart DA, Shimmin GA, Renfree M, Paris MCJ. Anatomical considerations for the development of artificial insemination by catheter in two marsupials. Theriogenology 2003;59:401.

[78] Bodetti TJ, Hengstberger K, Johnston SD, Timms P. Evaluation of four antibiotics, tetracycline, erythromycin, penicillin and 
streptomycin for their ability to decontaminate Chlamydiaspiked koala (Phascolarctos cinereus) semen in vitro. Vet Rec 2003;155:588-91.

[79] Bodetti TJ, Johnston SD, Pospischil A, Knox C, Timms C. PCR detection of Chlamydia in koala (Phascolarctos cinereus) semen. Vet Rec 2002;151:147-9.

[80] Smith MJ. Establishment of a captive colony of Bettongia tropica (Marsupialia: Potoroidae) by cross fostering; and observations on reproduction. J Zool 1998;244:43-50.

[81] Friend T. Cross fostering Gilberts potoroo. Landscope 2008;23: 6-8.

[82] Jones M, Taggart DA, Temple-Smith P. Age determination and growth in wild Petrogale lateralis pearsoni and captive Petrogale lateralis 'MacDonnell Ranges race'. Aust J Zool 2004;52: 447-61.

[83] Taggart DA, Schultz DJ, Fletcher TP, Freind T, Smith I, Breed WG, et al. Cross fostering and pouch young isolation in macropodoid marsupials: implications for conservation and species management. In: Elderidge M, Coulson G, editors. Macropod symposium. Marrickville: Southwood Press; 2008.

[84] Taggart DA, Shimmin GA, Underwood G, Phillips K. Survival of very small macropod pouch young following short-term isolation from the pouch at various environmental temperatures. Anim Conserv 2002;5:275-82.

[85] Merchant JC, Sharman G. Observations on the attachment of marsupial pouch young to the teats and on the rearing of pouch young by foster-mothers of the same or different species. Aust J Zool 1966;14:593-609.

[86] Duckworth JA, Wilson K, Cui X, Molinia FC, Cowan PE. Immunogenicity and contraceptive potential of three infertilityrelevant zona pellucida 2 epitopes in the marsupial brushtail possum (Trichosurus vulpecula). Reproduction 2007;133: $177-86$.

[87] Samollow P. Status and applications of genomic resources for the gray, short-tailed opossum, Monodelphis domestica, an American marsupial model for comparative biology. Aust $\mathrm{J}$ Zool 2006;54:173-96.

[88] Keeley T. Development of short-term sperm storage technology for the Tasmanian devil. In: ARAZPA conference; 2008.

[89] Jungnickel MK, Hinds LA. Hormonal profiles in the tammar wallaby, Macropus eugenii, following FSH/LH superovulation. Reprod Fertil Dev 2000;12:457-64.

[90] Hickford DE, Merry NE, Johnson MH, Selwood L. Induced ovulation, mating success and embryonic development in the stripe-faced dunnart, Sminthopsis macroura. Reproduction 2001;122:777-83.

[91] Rodger JC, Breed WG, Bennet JH. Gonadotrophin-induced oestrus and ovulation in the polyovulatory marsupial Sminthopsis crassicaudata. Reprod Fertil Dev 1992;4:145-52.

[92] Magarey GM, Rodger JC, Buist JM, Mate KE. Effects of repeated superovulation and surgical oocyte collection on ovarian response and natural breeding ability of the tammar wallaby (Macropus eugenii). Reproduction 2003;125:701-7.

[93] Poole WE, Westcott M, Simms NG. Determination of oestrus in the female Tammar, Macropus eugenii, by analysis of cellular composition of smears from the reproductive tract. Wildl Res 1992;19:35-46.

[94] West M, Galloway D, Shaw J, Trounson A, Paris MCJ. Oestrous cycle of the common wombat, Vombatus ursinus, in Victoria, Australia. Reprod Fertil Dev 2004;16:339-46.

[95] Druery GV, Taggart DA, Shimmin GA, Horsup AB, TempleSmith PD, Paris DBBP, et al. Time of ovulation and artificial insemination following superovulation in the southern hairynosed wombat, Lasiorhinus latifrons. Adv Ethol (Suppl Ethol) 2004;38:100

[96] Druery GV, Shimmin GA, Taggart DA, Temple-Smith PD, Breed WG, McDonald $\mathrm{CH}$, et al. Ovarian follicular superstimulation and oocyte maturation in the anoestrous southern hairy-nosed wombat, Lasiorhinus latifrons. Anim Reprod Sci 2007;99:363-76.

[97] Finlayson GR, Shimmin GA, Taggart DA, Skinner JF, Gilmore A, Paris MCJ. Oestrous cycle of captive southern hairy-nosed wombats (Lasiorhinus latifrons) in South Australia, Australia. Anim Reprod Sci 2006;95:295-306.

[98] Finlayson GR, Taggart DA, Shimmin GA, White CR, Dibben $\mathrm{R}$, Steele $\mathrm{V}$, et al. Pouch young removal and return to oestrus in wild southern hairy-nosed wombats (Lasiorhinus latifrons). Anim Reprod Sci 2007;100:216-22.

[99] McDonald CH, Taggart DA, Breed WG, Druery GV, Shimmin GA, Finlayson GR, et al. Effect of exogenous gonadotrophins on ovarian morphology and oocyte maturation in the southern hairy nosed wombat Lasiorhinus latifrons during the breeding season. Reprod Fertil Dev 2006;18: 477-84.

[100] Paris MCJ, White A, Reiss A, West M, Schwarzenberger F. Faecal progesterone metabolites and behavioural observations for the non-invasive assessment of oestrous cycles in the common wombat (Vombatus ursinus) and the southern hairynosed wombat (Lasiorhinus latifrons). Anim Reprod Sci 2002;72:245-57.

[101] West M, Lacham-Kaplan O, Cleary M, Galloway D, Shaw J, Trounson AO, et al. In vitro maturation and intracytoplasmic sperm injection of oocytes collected from hormonally stimulated common wombats, Vombatus ursinus. Anim Reprod Sci 2007;98:311-21.

[102] Glazier AM. Seasonal variation in ovarian response to pregnant mares serum gonadotrophin in the brushtail possum (Trichosurus vulpecula). Reprod Fertil Dev 1998;10:499-503.

[103] Herbert CA, Trigg TE, Renfree MB, Shaw G, Eckery DC, Cooper DW. Long-term effects of deslorelin implants on reproduction in the female tammar wallaby (Macropus eugenii). Reproduction 2005;129:361-9.

[104] Nave CD, Shaw G, Short RV, Renfree MB. Contraceptive effects of levonorgestrel implants in a marsupial. Reprod Fertil Dev 2000;12:81-6.

[105] Magarey GM, Mate KE. Timing and ultrastructure of events following intracytoplasmic sperm injection in a marsupial, the tammar wallaby (Macropus eugenii). Reprod Fertil Dev 2003;15:397-406

[106] Richings NM, Shaw G, Temple-Smith PD, Renfree MB. Intracytoplasmic sperm injection in a marsupial. Reproduction 2004;128:595-605.

[107] Pukazhenthi BS, Wildt DE. Which reproductive technologies are most relevant to studying, managing and conserving wildlife. Reprod Fertil Dev 2004;16:33-46.

[108] Yanagimachi R. Intracytoplasmic injection of spermatozoa and spermatogenic cells: its biology and applications in humans and animals. RBM Online 2005;10:247-88.

[109] Liu JL, Kusakabe H, Chang CC, Suzuki H, Schmidt DW, Julian $\mathrm{M}$, et al. Freeze-dried sperm fertilization leads to full-term development in rabbits. Biol Reprod 2004;70: 1776-81.

[110] Ogonuki N, Mochida K, Miki H, Inoue K, Fray M, Iwaki T, et al. Spermatozoa and spermatids retrieved from frozen repro- 
ductive organs or frozen whole bodies of male mice can produce normal offspring. Proc Natl Acad Sci USA 2007;103: 13098-103.

[111] Retief JD, Krajewski C, Westerman M, Dixon GH. The evolution of protamine P1 genes in dasyurid marsupials. J Mol Evol 1995;41:549-55.
[112] Kaneko T, Whittingham DG, Overstreet JW, Yanagimachi R. Tolerance of the mouse sperm nuclei to freeze-drying depends on their disulfide status. Biol Reprod 2003;69:1859-62.

[113] Czarny NA, Harris MS, Rodger JC. Preservation of spermatozoa from dasyurid marsupials.. In: Proceedings of the Society of Reproductive Biology Annual Scientific Meeting; 2007. 